\title{
Enthalpies of Dilution of Aqueous Electrolytes: Sulfuric Acid, Hydrochloric Acid, and Lithium Chloride
}

\author{
Y. C. Wu \\ Center for Consumer Technology, National Bureau of Standards, Washington, DC 20234 \\ and \\ T. F. Young* \\ G. H. Jones Laboratory, University of Chicago, Chicago, Illinois 60637
}

August 8, 1979

\begin{abstract}
Calorimetric measurements at $25{ }^{\circ} \mathrm{C}$ of the enthalpies of dilution of aqueous $\mathrm{H}_{2} \mathrm{SO}_{4}(0.00090$ to 6.4 $\left.\mathrm{mol} \cdot \mathrm{kg}^{-1}\right)$, $\mathrm{LiCl}\left(0.026\right.$ to $\left.6.7 \mathrm{~mol} \cdot \mathrm{kg}^{-1}\right)$, and $\mathrm{HCl}\left(0.018\right.$ to $\left.1.6 \mathrm{~mol} \cdot \mathrm{kg}^{-1}\right)$ have been performed using two different isothermal calorimeters. The results of this work and that of three earlier calorimetric investigations and one Raman spectral investigation have been used to calculate values of the relative apparent molal enthalpies, and relative partial molal enthalpies for these electrolytes.
\end{abstract}

Key words: Calorimetry; electrolytes; enthalpy of dilution; heat; hydrochloric acid; lithium chloride; relative apparent molal enthalpy; relative partial molal enthalpy; sulfuric acid; thermochemistry.

\section{Introduction}

The relative apparent molal enthalpy $\left(\Phi_{L}\right)^{1}$ or heat content of sulfuric acid is a complicated function of the molality. The determination of this quantity requires an extrapolation of enthalpies of dilution as measured down to extremely low molalities.

There have been numerous reports and discussions of the relative apparent molal enthalpy of sulfuric acid [1-4]. ${ }^{2}$ At the extreme dilutions attainable experimentally, sulfuric acid is known to have undissociated bisulfate ions [2]. This incomplete dissociation at the lowest dilutions complicates the extrapolation procedure, causes deviations from the Debye-Huckel limiting law (DHLL), and makes the final calculated values of the relative apparent molal enthalpy dependent on the method of data treatment.

Young and Blatz [2] performed an analysis of this problem in 1949. They took the degree of dissociation, and thence the enthalpy of dissociation, into consideration and

\footnotetext{
* Late professor of chemistry at the University of Chicago.

'The reader is referred to the treatise of Harned and Owen [1] for the definition of the terms used in this paper and to the glossary (sect. 6) for an explanation of the symbols which we have used.

${ }^{2}$ Figures in brackets indicate references at the end of this paper.
}

performed a semi-theoretical calculation of the relative apparent molal enthalpy of sulfuric acid. They also found a systematic difference of 460 calories $(1 \mathrm{cal}=4.184 \mathrm{~J})$ between their values and those reported in the literature [5]. This discrepancy was also confirmed later by Harned and Owen [1]. Several years later, Giauque and his co-workers at the University of California began an analysis of the thermodynamics of sulfuric acid [6]. Thus, the work of Young and Blatz [2], the research of Giauque et al., and the earlier measurements of Groenier and Young [7] indicated a need for additional experimental work on the dilution enthalpy of sulfuric acid which, in turn, led the junior author (YCW) to undertake this investigation, which also included measurements on aqueous $\mathrm{HCl}$ and $\mathrm{LiCl}$, as a part of his Ph.D. dissertation. While some of the results obtained herein have been cited by Giauque et al. [6] and used both in the $\mathrm{Na}$ tional Bureau of Standards Technical Note 270 Series [3], and in the review of Pitzer et al. [8], independent publication of the results was delayed by circumstances encountered by the senior author (TFY). Publication at this time serves both to better document the experimental results and the method of data treatment and to honor the memory of the late T. F. Young and his dedication to science. 


\section{Experimental Procedure}

Two calorimeters of different sensitivities were employed depending on the molality. A calorimeter with lower sensitivity, as described by Young and his co-workers [9, 10], was used for most of the measurements where the molality was greater than $0.01 \mathrm{~mol} \mathrm{~kg}^{-1}$. For those measurements below $0.01 \mathrm{~mol} \mathrm{~kg}^{-1}$, a more sensitive differential calorimeter was necessary. The latter instrument contained a thermel of 500 junctions on each side of a plastic plate which was held by petroleum "wax" in the center of a large Dewar flask having a volume of two liters. Its design was somewhat similar to that of the calorimeter used by Lange and his co-workers [11]. Details of the construction and operation have been described by Fagley [12] and Kasner [13].

All of the chemicals used in this study were purchased from Baker Chemical Company" as "Chemically Pure Analyzed Reagents." Relatively concentrated stock solutions were prepared and were analyzed by standard methods. The two acids were analyzed by titration with sodium hydroxide which had been standardized with potassium acid phthalate using phenolphthalein as an end-point indicator. The hydrochloric acid and the lithium chloride were analyzed gravimetrically by precipitation as silver chloride. Sulfuric acid was also analyzed by measurement of its density and comparison with data given in the International Critical Tables [14]. Duplicate analyses and analyses with different methods agreed to within 0.1 percent (for all stock solutions). All stock solutions were further diluted by mass to the various molalities necessary for each experiment. Some of the solutions produced during the dilution experiments were subjected to additional tests of analytical accuracy.

The laboratory's distilled water was further purified before use by redistillation with alkaline permanganate in a block-tin still [13]. The specific conductance of all water used was lower than $10^{-6} \mathrm{ohm}^{-1} \cdot \mathrm{cm}^{-1}$.

The temperature sensitivity of the differential calorimeter was about $2 \mu \mathrm{K}$, which corresponds to an uncertainty in the heat measurement of 1.5 mcal. At a molality of 0.001 $\mathrm{mol} \cdot \mathrm{kg}^{-1}$, the heat liberated on dilution of sulfuric acid was about 50 mcal with a corresponding uncertainty of 3 percent. For lower molalities, the heat liberated would have decreased, thus magnifying the relative error. Therefore, the heat of dilution at $0.001 \mathrm{~mol} \cdot \mathrm{kg}^{-1}$ was about the limit that this could be measured using the then existing instrumentation.

The temperature sensitivity of the less sensitive calorimeter was about $20 \mu \mathrm{K}$, which corresponded to a sensitivity in the heat measurement of 15 mcal. Thus, for the enthalpy of

\footnotetext{
${ }^{3}$ Certain commercial materials are identified in this paper in order to adequately specify the experimental procedures. Such identification does not imply recommendation or endorsement by the National Bureau of Standards.
}

dilution of $\mathrm{HCl}$ at about $0.02 \mathrm{~mol} \cdot \mathrm{kg}^{-1}$, where the heat liberated was about $60 \mathrm{mcal}$, the corresponding uncertainty is about 25 percent. However, the heat liberated for the enthalpy of dilution of sulfuric acid in the same molality range was about fifty times larger and the corresponding uncertainty was less than 1 percent.

\section{Results and Calculation}

The method of treating the data is essentially the same as described previously [10]. The molalities of the initial and final solutions are, respectively, $m_{1}$ and $m_{2}$. The heat absorbed is $Q$, and $Q$ divided by the number of moles contained in the solution is the enthalpy of dilution from $m_{1}$ to $m_{2}, \Delta \Phi_{L} / \Delta m^{1 / 2}$. The derivative of $\Phi_{L}$ with respect to $m^{1 / 2}$ is $S$, which can be obtained from a "chord-area" plot [15, 16]. The experimental data are given in tables 1,2 and 3 and in figures 1 and 2, where, for sulfuric acid, we also show the data of Groenier [7], of Lange et al. [5], and of Giauque et $a l$. [6]. In order to calculate $\Phi_{L}$ at a given molality using the relationship

$$
\Phi_{L}=\int_{o}^{m} \frac{d \Phi_{L}}{d m^{1 / 2}} d m^{1 / 2},
$$

it is necessary to provide some form of extrapolation to zero molality to aid in the integration of the chord-area plot. For $\mathrm{HCl}$ and $\mathrm{LiCl}$, we have used the Debye-Huckel limiting law (DHLL) value of $S^{\circ}$ of $477 \mathrm{cal} \cdot \mathrm{mol}^{-1 / 2} \mathrm{~kg}^{1 / 2}$ [16].

For $\mathrm{H}_{2} \mathrm{SO}_{4}$ the situation is more complex and warrants additional discussion. From Debye-Huckel theory, $S^{\circ}$ for a $2-1$ electrolyte is $2480 \mathrm{cal} \cdot \mathrm{mol}^{-3 / 2} \cdot \mathrm{kg}^{1 / 2}$ [2]. In order to join this value with the experimental data in figure la, we consider one mole of $\mathrm{H}_{2} \mathrm{SO}_{4}$ to be a mixture of $\alpha$ moles of $\mathrm{H} \cdot \mathrm{H} \cdot \mathrm{SO}_{4}$ and $(1-\alpha)$ moles of $\mathrm{H} \cdot \mathrm{HSO}_{4}$, where the dot between the symbols indicates the dissociation which has occurred. The relative apparent molal enthalpy of sulfuric acid will be

$$
\begin{gathered}
\Phi_{L}\left(\mathrm{H}_{2} \mathrm{SO}_{4}\right)=\alpha \Phi_{L}\left(\mathrm{H} \cdot \mathrm{H} \cdot \mathrm{SO}_{4}\right)+ \\
(1-\alpha) \Phi_{L}\left(\mathrm{H} \cdot \mathrm{HSO}_{4}\right)+(1-\alpha) \Delta H_{D i s s}^{\circ}+\Delta_{m} H
\end{gathered}
$$

$\alpha$ has been evaluated by Young and Blatz [2] from Raman spectral data; we have taken the enthalpy of dissociation of bisulfate ion at infinite dilution $\left(\Delta H_{D i s s}^{\circ}\right)$ as $5200 \mathrm{cal} \cdot \mathrm{mol}^{-1}$ [1]; we have estimated $\Phi_{L}$ for $\left(\mathrm{H} \cdot \mathrm{H} \cdot \mathrm{SO}_{4}\right)$ from the $\Phi_{L}$ data for $\mathrm{Li}_{2} \mathrm{SO}_{4}[1]$; we have used an average $\Phi_{L}$ for $\mathrm{HCl}$ and $\mathrm{LiCl}$ obtained in this investigation (see tables 6 and 7 and reference [17]) in estimating a value of $\Phi_{L}$ for $\left(\mathrm{H} \cdot \mathrm{HSO}_{4}\right)$; and we have taken the enthalpy of mixing of the ions $\left(\Delta_{m} H\right)$ to be zero [10]. The results of our semi-theoretical calculations for $\Phi_{L}$ and $S$ for $\mathrm{H}_{2} \mathrm{SO}_{4}$ are shown in table 4; the theoretical 
TABLE 1. Experimental dilution enthalpies for aqueous $\mathrm{H}_{2} \mathrm{SO}_{4}$ at $25^{\circ} \mathrm{C}$.

\begin{tabular}{|c|c|c|c|}
\hline$m_{1}^{1 / 2}$ & $m_{2}^{1 / 2}$ & $\Delta H_{D i l}$ & $\frac{\Delta H_{D i l}}{\Delta m^{1 / 2}}$ \\
\hline $\mathrm{mol}^{1 / 2} \cdot \mathrm{kg}^{-1 / 2}$ & $\mathrm{~mol}^{1 / 2} \cdot \mathrm{kg}^{-1 / 2}$ & $\mathrm{cal} \cdot \mathrm{mol}^{-1}$ & $\mathrm{cal} \cdot \mathrm{mol}^{-3 / 2} \cdot \mathrm{kg}^{1 / 2}$ \\
\hline 0.031705 & 0.030134 & -52.85 & 33649 \\
\hline .033214 & $.031637^{\mathrm{a}}$ & -50.71 & 32170 \\
\hline .040484 & .038529 & -66.61 & 34074 \\
\hline .041051 & .039057 & -65.49 & 32841 \\
\hline .056369 & .053568 & -83.86 & 29932 \\
\hline .056548 & .053796 & -78.62 & 28559 \\
\hline .095864 & .091232 & -93.33 & 20150 \\
\hline .100000 & .095259 & -93.38 & 19698 \\
\hline .21840 & .20680 & -83.67 & 7207.5 \\
\hline $.25180^{\mathrm{a}}$ & .23839 & -77.97 & 5814.8 \\
\hline .25180 & .23875 & -73.08 & 5602.5 \\
\hline .37394 & .35398 & -61.78 & 3094.8 \\
\hline .37900 & .35948 & -58.88 & 3017.3 \\
\hline .37900 & .35989 & -57.97 & 3035.0 \\
\hline .38659 & .36672 & -57.35 & 2886.1 \\
\hline .42253 & .40030 & -53.42 & 2403.3 \\
\hline .42253 & .40145 & -50.40 & 2390.4 \\
\hline .47311 & .44907 & -48.02 & 1997.7 \\
\hline .47311 & .44985 & -45.78 & 1967.9 \\
\hline .50564 & .48041 & -44.78 & 1774.5 \\
\hline .62997 & .59868 & -35.60 & 1137.9 \\
\hline .71542 & .68034 & -31.73 & 904.7 \\
\hline 1.0934 & 1.0328 & -35.26 & 581.6 \\
\hline 1.0934 & 1.0349 & -34.04 & 581.8 \\
\hline 2.5344 & 2.3640 & -352.88 & 2071.6 \\
\hline
\end{tabular}

a Numbers followed by an (a) indicate corrections for typographical errors in the thesis [18].

TABLE. 2. Experimental dilution enthalpies for aqueous $\mathrm{HCl}$ at $25^{\circ} \mathrm{C}$.

\begin{tabular}{|c|c|c|c|}
\hline$m_{1}^{1 / 2}$ & $m_{2}^{1 / 2}$ & $\Delta H_{D i l}$ & $\frac{\Delta H_{D i l}}{\Delta m^{1 / 2}}$ \\
\hline $\mathrm{mol}^{1 / 2} \cdot \mathrm{kg}^{-1 / 2}$ & $\mathrm{~mol}^{1 / 2} \cdot \mathrm{kg}^{-1 / 2}$ & $\mathrm{cal} \cdot \mathrm{mol}^{-1}$ & $\mathrm{cal} \cdot \mathrm{mol}^{-3 / 2} \cdot \mathrm{kg}^{1 / 2}$ \\
\hline 0.14135 & 0.13470 & -2.980 & 448.6 \\
\hline .14452 & .13726 & -2.840 & 390.8 \\
\hline .14686 & .13960 & -3.529 & 485.6 \\
\hline .20265 & .19297 & -4.000 & 412.9 \\
\hline .33828 & .32164 & -6.437 & 386.9 \\
\hline .39926 & .37870 & -8.089 & 393.4 \\
\hline .39926 & .37920 & -8.597 & $428.7^{\mathrm{a}}$ \\
\hline .49188 & .46675 & -9.347 & 371.9 \\
\hline .50776 & .48089 & -10.338 & 384.6 \\
\hline .55953 & .53240 & -10.242 & 377.4 \\
\hline .56746 & .53842 & -11.280 & 388.3 \\
\hline .82167 & .77934 & -17.686 & 417.8 \\
\hline .82167 & .78062 & -17.452 & 425.1 \\
\hline .88163 & .83422 & -20.258 & 427.2 \\
\hline 1.2592 & 1.1978 & -33.786 & 549.5 \\
\hline 1.2592 & 1.1953 & -34.469 & 539.3 \\
\hline
\end{tabular}

a This point was taken to be an outlier and was given zero weight in the construction of the chord area plot. curve is the solid curve from zero to $0.30 \mathrm{~mol}^{1 / 2} \cdot \mathrm{kg}^{-1 / 2}$ shown in figure la. Since this semi-theoretical curve, based upon the above auxiliary information and assumptions, is seen to be in good agreement with the experimental data from 0.04 to $0.30 \mathrm{~mol}^{1 / 2} \cdot \mathrm{kg}^{-1 / 2}$, we feel reasonably confident in relying upon it in the low molality region to perform the integration of the chord-area plot in obtaining $\Phi_{L}$ values for $\mathrm{H}_{2} \mathrm{SO}_{4}$.

TABLE 3. Experimental dilution enthalpies for aqueous $\mathrm{LiCl}$ at $25^{\circ} \mathrm{C}$.

\begin{tabular}{|c|c|c|c|}
\hline$m_{1}^{1 / 2}$ & $m_{2}^{1 / 2}$ & $\Delta H_{D i l}$ & $\frac{\Delta H_{D i l}}{\Delta m^{1 / 2}}$ \\
\hline $\mathrm{mol}^{1 / 2} \cdot \mathrm{kg}^{-1 / 2}$ & $\mathrm{~mol}^{1 / 2} \cdot \mathrm{kg}^{-1 / 2}$ & $\mathrm{cal} \cdot \mathrm{mol}^{-1}$ & $\mathrm{cal} \cdot \mathrm{mol}^{-3 / 2} \cdot \mathrm{kg}^{1 / 2}$ \\
\hline 0.50658 & $0.16218^{\mathrm{a}}$ & -112.95 & 327.96 \\
\hline .53508 & .50658 & -8.310 & 291.57 \\
\hline .80307 & .75627 & -12.764 & 272.75 \\
\hline 1.0000 & .94600 & -15.745 & 291.57 \\
\hline 1.2898 & 1.2165 & -16.237 & 358.04 \\
\hline 1.3381 & 1.2568 & -28.573 & 351.62 \\
\hline 1.4394 & 1.3475 & -34.947 & 380.31 \\
\hline 1.9716 & 1.8614 & -64.330 & 583.81 \\
\hline 2.5982 & 2.4359 & -148.75 & $916.59 \mathrm{~b}$ \\
\hline
\end{tabular}

a Typographical error in the thesis [18].

b This point is not shown in figure 2 .

TABLE 4. Calculated values of $\Phi_{L}$ and $\mathrm{S}$ for $\mathrm{H}_{2} \mathrm{SO}_{4}$ at $25^{\circ} \mathrm{C}$.

\begin{tabular}{|c|c|c|c|}
\hline$I_{m}^{1 / 2 \mathrm{a}}$ & $m^{1 / 2}$ & $\Phi_{L}$ & $S$ \\
\hline $\mathrm{mol}^{1 / 2} \cdot \mathrm{kg}^{-1 / 2}$ & $\mathrm{~mol}^{1 / 2} \cdot \mathrm{kg}^{-1 / 2}$ & $\mathrm{cal} \cdot \mathrm{mol}^{-1}$ & $\mathrm{cal} \cdot \mathrm{mol}^{-3 / 2} \cdot \mathrm{kg}^{1 / 2}$ \\
\hline 0.00 & 0.00000 & 0 & 2480 \\
\hline .01 & .005785 & 46.68 & 12953 \\
\hline .02 & .011639 & 150.48 & 21783 \\
\hline .04 & .023754 & 481.42 & 31254 \\
\hline .06 & .036638 & 903.65 & 33298 \\
\hline .08 & .050421 & 1350.71 & 33183 \\
\hline .10 & .065126 & 1782.05 & 27437 \\
\hline .12 & .080702 & 2177.65 & 23425 \\
\hline .14 & .097064 & 2529.63 & 19725 \\
\hline .16 & .114108 & 2837.89 & 16561 \\
\hline .18 & .131743 & 3105.71 & 13943 \\
\hline .20 & .149845 & 3337.80 & 11781 \\
\hline .22 & .168356 & 2539.05 & 10031 \\
\hline .24 & .18720 & 3714.08 & 8604.8 \\
\hline .26 & .20630 & 3866.97 & 7454.2 \\
\hline .28 & .22563 & 4001.22 & 6484.0 \\
\hline .30 & .24513 & 4119.73 & 5691.9 \\
\hline .32 & .26478 & 4225.00 & 5038.8 \\
\hline .34 & .28455 & 4319.00 & 4490.1 \\
\hline .36 & .30441 & 4403.45 & 4028.6 \\
\hline .38 & .32436 & 4479.47 & 3634.4 \\
\hline .40 & .34437 & 4549.00 & - \\
\hline
\end{tabular}

a The values of the ionic strength given in column one were calculated using the relationship $I_{m}=1 / 2 \Sigma \mathrm{m}_{i} Z_{i}^{2}$, where the summation is over the ions $\mathrm{H}^{+}, \mathrm{HSO}_{4}^{-}$, and $\mathrm{SO}_{4}^{2-}$, i.e. cognizance is taken of the incomplete dissociation of the bisulfate ion. Thus, $I=(1+2 \alpha) m$. 

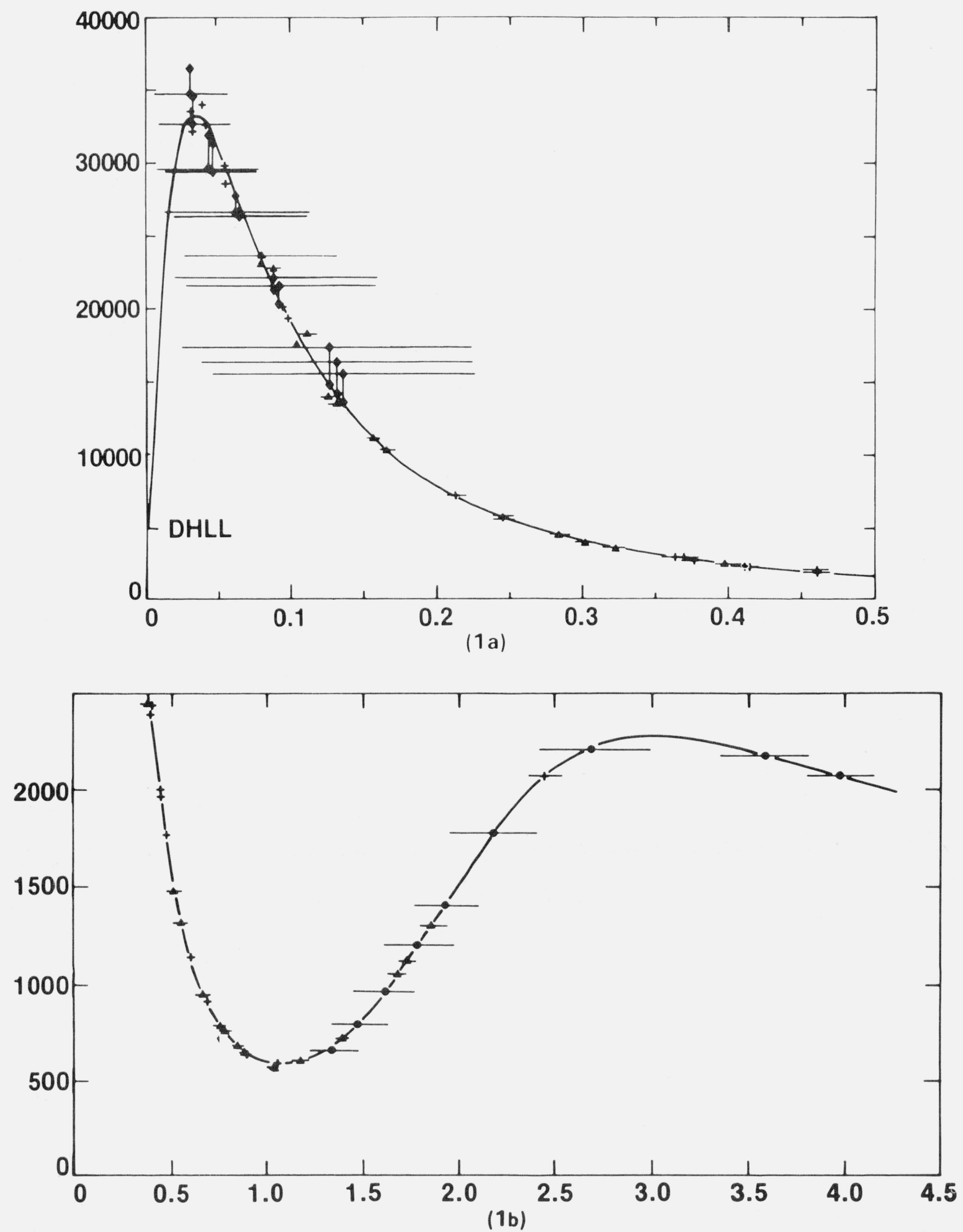

Figures la and lb. Plots of $\mathrm{S}\left(\mathrm{cal} \cdot \mathrm{mol}^{-3 / 2} \cdot \mathrm{kg}^{1 / 2}\right)$ as a function of $\mathrm{m}^{1 / 2}\left(\mathrm{~mol}^{1 / 2} \cdot \mathrm{kg}^{-1 / 2}\right)$ for aqueous $\mathrm{H}_{2} \mathrm{SO}_{4}$ at $25^{\circ} \mathrm{C}$.

+ indicates the experimental data of this investigation, - indicates the results of Groenier [7], - indicates the results of Lange, Monheim, and Robinson [5] and $\bullet-$ indicates the results of Giauque et al. [6]. The solid curve from zero to $0.3 \mathrm{~mol}^{-1 / 2} \cdot \mathrm{kg}^{-1 / 2}$ was calculated semi-theoretically using equation 2 and the rest of the curve was drawn in accordance with the chord-area principle [15, 16]. For each of the long-chords there are two points: one indicates the center of the chord and the other is corrected for curvature [16], i.e. the true derivative $\left(d \Phi_{L} / d m^{1 / 2}\right.$ is not equal to $\left.\Delta \Phi_{L} / \Delta m^{1 / 2}\right)$ should pass through each chord such that the two areas enclosed between the curve, the chord, and vertical lines drawn through the ends of the chord are equal. Note that the ordinate scales for figure la and $\mathrm{lb}$ differ by a factor of a bout 12 ; the contraction or expansion of those curves is apparent. 


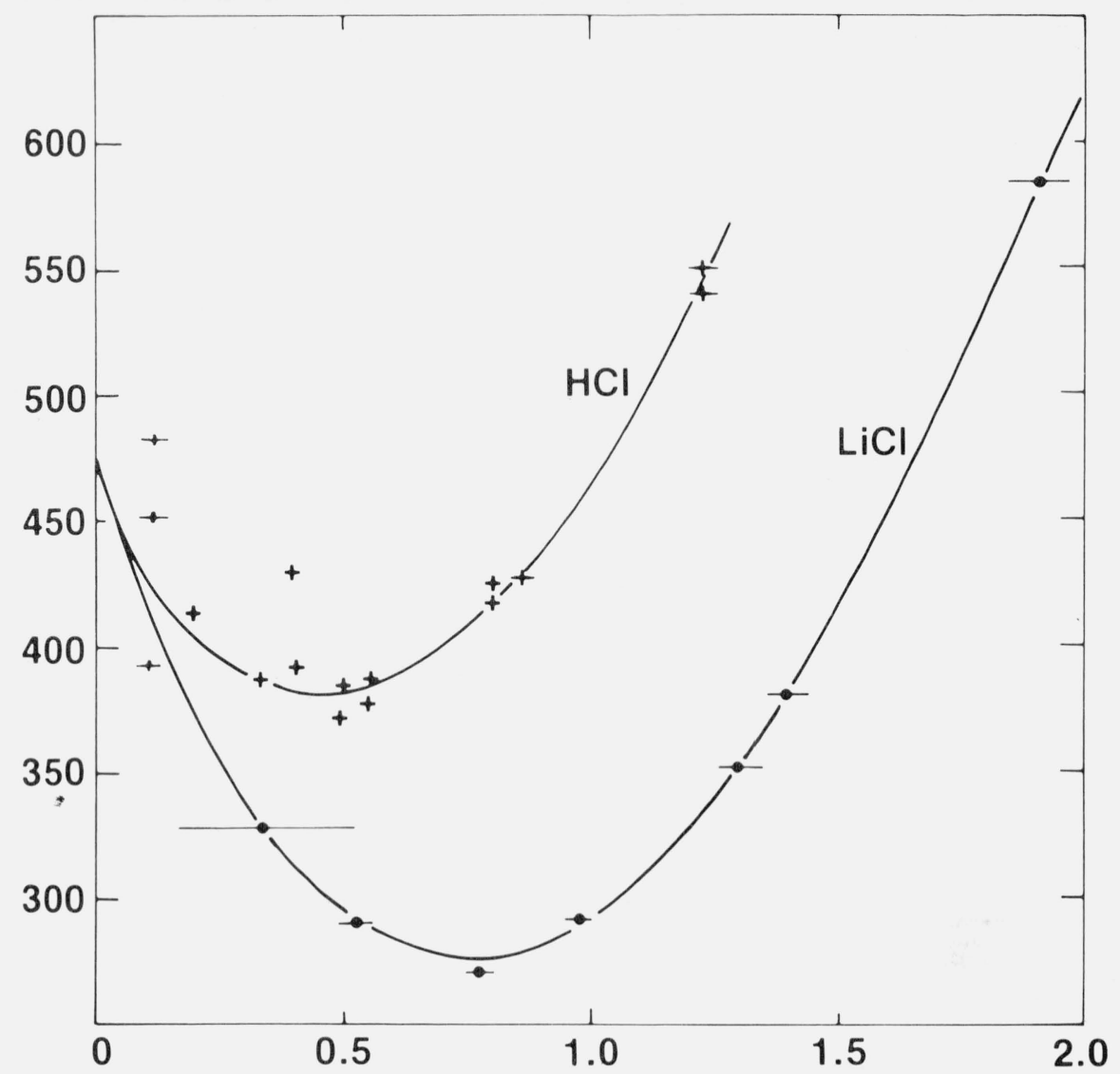

Tables 5, 6 and 7 give values of $\Phi_{L}$ for aqueous $\mathrm{H}_{2} \mathrm{SO}_{4}$, $\mathrm{LiCl}$, and $\mathrm{HCl}$ calculated using eq (1) and values of $\bar{L}_{1}$ and $\bar{L}_{2}$ calculated using the relationships:

$$
\bar{L}_{1}=-\frac{M_{1} m^{3 / 2} S}{2000}
$$

and

$$
\bar{L}_{2}=\Phi_{L}+1 / 2 m^{1 / 2} S
$$

It is interesting to note that our values of $\Phi_{L}$ for aqueous $\mathrm{HCl}$ compare very well with those "best values" compiled by Parker [17]. Our corresponding values for $\mathrm{LiCl}$ are somewhat higher than those given by Parker; the discrepancy has been discussed by Wu and Friedman [19].

\section{Glossary}

$H=$ enthalpy or heat content

$I_{m}=$ ionic strength on the molality scale: $I_{m}=\frac{1}{2} \Sigma m_{i} Z_{i}^{2}$
$\bar{L}_{i}=$ relative partial molal enthalpy of ith component $m=$ molality

$M_{1}=$ molecular weight of the solvent $\left(18.015 \mathrm{~g} \cdot \mathrm{mol}^{-1}\right)$

$Q=$ heat

$S=\mathrm{d} \Phi_{L} / d m^{1 / 2}$

$Z_{i}=$ charge of an ion $i$

$\alpha=$ degree of dissociation

$\Phi_{L}=$ relative apparent molal enthalpy

The junior author (YCW), wishes to express his sincere appreciation to Dr. Robert N. Goldberg for his valuable discussions throughout the preparation of the manuscript, and to $\mathrm{Mr}$. Walter Leight for his encouragement to document these results. He also thanks Mrs. Louise Shannon and Mrs. Pamela Tyeryar for their efforts in typing the manuscript. 
TABLE 5. Values of $\Phi_{L}, \bar{L}_{1}$, and $\bar{L}_{2}$ for aqueous $\mathrm{H}_{2} \mathrm{SO}_{4}$ at $25^{\circ} \mathrm{C}$

\begin{tabular}{|c|c|c|c|}
\hline$m^{1 / 2}$ & $\Phi_{L}$ & $I_{R}$ & $\overline{L_{2}}$ \\
\hline $\mathrm{mol}^{1 / 2} \cdot \mathrm{kg}^{-1 / 2}$ & $\mathrm{cal} \cdot \mathrm{mol}^{-1}$ & $\mathrm{cal} \cdot \mathrm{mol}^{-1}$ & $\mathrm{cal} \cdot \mathrm{mol}^{-1}$ \\
\hline 0.005 & 40 & 69.5 & -0.00001 \\
\hline .01 & 120 & 215.5 & -.00017 \\
\hline .02 & 370 & 663.0 & -.0021 \\
\hline .03 & 680 & 1173.5 & -.0080 \\
\hline .04 & 1015 & 1676.0 & -.0190 \\
\hline .05 & 1340 & 2120.0 & -.0351 \\
\hline .06 & 1640 & 2498 & -.0557 \\
\hline .07 & 1910 & 2822 & -.0805 \\
\hline .08 & 2160 & 3104 & -.1088 \\
\hline .09 & 2380 & 3336 & -.1395 \\
\hline .10 & 2585 & 3540 & -.1721 \\
\hline .12 & 2935 & 3874 & -.2436 \\
\hline .14 & 3220 & 4120 & -.3176 \\
\hline .16 & 3450 & 4310 & -.3966 \\
\hline .18 & 3650 & 4469 & -.4781 \\
\hline .20 & 3820 & 4605 & -.5657 \\
\hline .22 & 3965 & 4708 & -.6475 \\
\hline .24 & 4090 & 4800 & -.7366 \\
\hline .26 & 4200 & 4879 & -.8265 \\
\hline .28 & 4300 & 4850 & -.9180 \\
\hline .30 & 4370 & 4990 & -1.0004 \\
\hline .35 & 4550 & 5100 & -1.214 \\
\hline .40 & 4690 & 5184 & -1.424 \\
\hline .45 & 4801 & 5250 & -1.535 \\
\hline .50 & 4892 & 5303 & -1.852 \\
\hline .55 & 4969 & 5345 & -2.060 \\
\hline .60 & 5031 & 5382 & -2.276 \\
\hline .65 & 5086 & 5415 & -2.499 \\
\hline .70 & 5133 & 5446 & -2.766 \\
\hline .75 & 5175 & 5475 & -3.040 \\
\hline .80 & 5214 & 5506 & -3.367 \\
\hline .85 & 5249 & 5547 & -3.756 \\
\hline .90 & 5282 & 5566 & -4.149 \\
\hline .95 & 5312 & 5598 & -4.650 \\
\hline 1.00 & 5342 & 5634 & -5.262 \\
\hline 1.10 & 5400 & 5719 & -6.954 \\
\hline 1.20 & 5460 & 5822 & -9.401 \\
\hline 1.30 & 5522 & 5942 & -12.79 \\
\hline 1.40 & 5589 & 6086 & -17.55 \\
\hline 1.50 & 5665 & 6273 & -24.63 \\
\hline 1.60 & 5752 & 6500 & -34.50 \\
\hline 1.70 & 5852 & 6762 & -47.36 \\
\hline 1.80 & 5967 & 7056 & -63.56 \\
\hline 1.90 & 6095 & 7377 & -83.41 \\
\hline 2.00 & 6237 & 7737 & -108.1 \\
\hline 2.20 & 6567 & 8536 & -171.7 \\
\hline 2.40 & 6958 & 9366 & -250.9 \\
\hline 2.60 & 7368 & 10196 & -344.4 \\
\hline 3.00 & 8267 & 11695 & -555.6 \\
\hline
\end{tabular}

TABLE 6. Values of $\Phi_{L}, \bar{L}_{1}$, and $\vec{L}_{2}$ for aqueous $\mathrm{HCl}$ at $25^{\circ} \mathrm{C}$.

\begin{tabular}{c|c|c|c}
\hline \hline $\mathrm{m}^{1 / 2}$ & $\Phi_{L}$ & $\overline{L_{1}}$ & $\overline{L_{2}}$ \\
$\mathrm{~mol}^{1 / 2} \cdot \mathrm{kg}^{-1 / 2}$ & $\mathrm{cal} \cdot \mathrm{mol}^{-1}$ & $\mathrm{cal} \cdot \mathrm{mol}^{-1}$ & $\mathrm{cal} \cdot \mathrm{mol}^{-1}$ \\
\hline 0.1 & 45.53 & 67.01 & -0.0039 \\
.2 & 87.30 & 127.9 & -.0292 \\
.3 & 127.1 & 185.6 & -.0949 \\
.4 & 165.7 & 242.2 & -.2201 \\
.5 & 203.8 & 299.1 & -.4290 \\
.6 & 242.3 & 353.6 & -.7545 \\
.7 & 281.7 & 422.0 & -1.238 \\
.8 & 322.6 & 489.6 & -1.925 \\
.9 & 365.4 & 562.6 & -2.877 \\
.0 & 410.6 & 643.0 & -4.187 \\
1.1 & 458.6 & 732.1 & -5.961 \\
1.2 & 510.3 & 831.5 & -8.334 \\
\hline
\end{tabular}

TABLE 7. Values of $\Phi_{L}, \vec{L}_{4}$, and $\vec{L}_{2}$ for aqueous LiCi at $25^{\circ} \mathrm{C}$.

\begin{tabular}{c|c|c|c}
\hline \hline$m^{1 / 2 \mathrm{a}}$ & $\Phi_{L}$ & $\overline{L_{1}}$ & $\overline{L_{2}}$ \\
$\mathrm{~mol}^{1 / 2} \cdot \mathrm{kg}^{-1 / 2}$ & $\mathrm{cal} \cdot \mathrm{mol}^{-1}$ & $\mathrm{cal} \cdot \mathrm{mol}^{-1}$ & $\mathrm{cal} \cdot \mathrm{mol}^{-1}$ \\
\hline 0.1 & 44.80 & 65.75 & -0.00377 \\
.2 & 84.37 & 121.6 & -.02684 \\
.3 & 119.9 & 162.6 & -.08216 \\
.4 & 152.4 & 214.9 & -.1801 \\
.5 & 182.7 & 256.4 & -.3317 \\
.6 & 211.6 & 296.5 & -.5506 \\
.7 & 239.6 & 336.4 & -.8546 \\
.8 & 267.2 & 377.4 & -1.2710 \\
.9 & 295.0 & 421.5 & -1.845 \\
1.0 & 323.7 & 469.7 & -2.630 \\
1.1 & 353.6 & 522.5 & -3.681 \\
1.2 & 385.3 & 581.5 & -5.090 \\
1.3 & 419.3 & 648.4 & -6.974 \\
1.4 & 456.1 & 723.9 & -9.457 \\
1.5 & 496.0 & 808.8 & -12.667 \\
1.6 & 539.7 & 904.3 & -16.817 \\
1.7 & 587.3 & 1009.8 & -21.995 \\
1.8 & 639.1 & 1123.5 & -28.274 \\
1.9 & 695.0 & 1246.6 & -35.872 \\
2.0 & 755.2 & 1378.6 & -44.924 \\
\hline
\end{tabular}

a We note that while the experimental data extend to $2.6 \mathrm{~mol}^{1 / 2} \cdot \mathrm{kg}^{-1 / 2}$, we have chosen to terminate this table at $2.0 \mathrm{~mol}^{1 / 2} \cdot \mathrm{kg}^{-1 / 2}$ rather than rely on only one measurement at $2.6 \mathrm{~mol}^{1 / 2} \cdot \mathrm{kg}^{-1 / 2}$. 


\section{References}

[1] Harned, H. S. and Owen, B. B., The Physical Chemistry of Electrolytic Solutions, 3rd ed., Reinhold Publishing Co., New York, 1958.

[2] Young, T. F. and Blatz, L. A., Chem. Rev., 44, 93 (1949).

[3] Wagman, D. D., Evans, W. H., Parker, V. B., Halow, I., Bailey, S. M. and Schumm, R., Selected Values of Chemical Thermodynamic Properties, Nat. Bur. Stand. (U.S.), Tech. Note 270-3, 273 pages (Jan. 1968).

[4] Smith-Magowan, D. S. and Goldberg, R. N., A Bibliography of Sources of Experimental Data Leading to Thermal Properties of Binary Aqueous Electrolyte Solutions, Nat. Bur. Stand. (U.S.), Spec. Publ. 537, 89 pages (March 1979).

[5] Lange, E., Monheim, J. and Robinson, A. L., J. Am. Chem. Soc., 55, 4733 (1933).

[6] Giauque, W. F., Hornung, E. W., Knuzler, J. E. and Rubin, T. R., J. Am. Chem. Soc. 82, 62 (1960).

[7] Groenier, W. L., Ph.D. Thesis, University of Chicago (1936); performed under the direction of Professor T. F. Young.
[8] Pitzer, K. S., Roy, R. N. and Silvester, L. F., J. Am. Chem. Soc. 99, 4930 (1977).

[9] Young, T. F. and Smith, B., J. Am. Chem. Soc. 58, 716 (1954).

[10] Young, T. F., Wu, Y. C. and Karwetz, A. A., Disc. Faraday Soc. No. 24, 37 (1957).

[11] Lange, E. and Robinson, A. L., Chem. Rev. 9, 89 (1931).

[12] Fagley, T. F., Ph.D. Thesis, University of Chicago (1949); performed under the direction of Professor T. F. Young.

[13] Kasner, F., Ph.D. Thesis, University of Chicago (1961); performed under the direction of Professor T. F. Young.

[14] International Critical Tables of Numerical Data, Physics, Chemistry, and Technology, Vol. III, p. 56, E. W. Washburn, editor-in chief, McGraw-Hill Book Co., Inc., New York (1930).

[15] Young, T. F. and Vogel, O. G., J. Am. Chem. Soc., 54, 3030 (1932).

[16] Young, T. F. and Groenier, W. L., J. Am. Chem. Soc., 58, 187 (1936).

[17] Parker, V. B., Thermal Properties of Aqueous Uni-univalent Electrolytes, Nat. Stand. Ref. Data Ser., Nat. Bur. Stand. (U.S.) 2, 71 pages (Apr. 1965).

[18] Wu, Y. C., Ph.D. Thesis, University of Chicago, Chicago, Illinois (1957).

[19] Wu, Y. C. and Friedman, H. L., J. Phys. Chem. 70, 166 (1966). 
